\title{
Strategies of Resistance and Disengagement in an Ethnic Enclave: El Barrio in Aurora, Illinois
}

\author{
Jack Thornburg \\ Benedictine University
}

This paper is a case study of a small city undergoing a process of demographic and ethnic change in community, empowerment, and political participation. For the dominant ethnic group these changes are threatening, but resisting the Latino community that they fear tends to set in motion the very conditions that exacerbate the growing prevalence of poverty and the attendant problems of gangs, domestic violence, and school drop-out rates. For the Latino community the challenge to such resistance is through community organizing and bringing pressure upon the city for inclusion in the political structure to influence policy regarding these problems. 


\section{Introduction}

This paper addresses the failure of political ethnic mobilization by a Latin American population near Chicago, Illinois, due to social and political elements beyond the control of Aurora's Mexican-American population. This essay will focus on education and the labor market as major social basics contributing to the structural position of the Latino population. As the Aurora labor market continues to transform to meet the needs of the "post-industrial" economy, the educational system takes on greater significance in training people for new employment opportunities. A bifurcated educational system based on ethnicity-middle class Whites in one and working class Latinos and Blacks in the other-operates to center the social problems associated with poverty, discrimination and cultural isolation in predominantly minority schools.

Aurora represents a classic case of Blauner's internal colony where an ethnic population is marginalized, impoverished, and discriminated against. Considering these objective conditions, the limited political response by the community to confront the issue of ethnic marginalization is problematic, especially considering the relative size of the Latino community. Political and economic power remains monopolized in the hands of the white majority, while among the lower classes in Aurora, primarily Latino and African American, there remains significant ethnic isolation that conforms to a system of ethnic stratification and social segregation.

For many U.S. ethnic communities the increase in economic globalization and the virtual collapse of the liberal corporate state has meant a restructuring of the political economy. Both business and government have broken the social contract with the poor, the disenfranchised, and organized labor. Government now takes a less active and direct role in providing public programs to address the issue of poverty and unemployment. In place of the contract a greater reliance is placed on the market and private initiative. Additionally, a new international regime has been instituted where production of goods has given way to service employment as industrial activity has either moved overseas or been computerized. This has a negative effect upon job opportunities and potential income. For example, Kent reports that "the movement from manufacturing 
to services has impacted real income levels; by 1987, shrinking industries paid $41.4 \%$ more in annual wages than did the expanding ones" (245). The structure now in place provides fewer employment opportunities for those not well educated and who have historically experienced discrimination. Song and Kim conclude that "the new U.S. political economy has functioned to intensify existing structural inequities in American society and to further rigidify ethnic stratification" (237). With higher school dropout rates, less "cultural capital" (that is, middle class parental skills, habits and styles that determine the cognitive skills of their children), and discrimination, various non-white ethnic groups find themselves with low paying jobs and stalled on the lower rungs of social mobility. The growth of technology and a global orientation may likewise further isolate ethnic groups since the dominant group, with its relative wealth and education, is most able to take advantage of the technological and global relationships, allowing them to further insulate and reorient their relationships and interests away from ethnic encounters.

Implicit bonds of language and culture, a set of common values and beliefs, and a shared sense of status hierarchy in the dominant social structure characterize the Latino community. The community, then, is a population whose members consciously identify with each other. But rather than view the Latino population of Aurora as a homogenous group or emphasize regional or interethnic differences (differences between Puerto Rican and Mexican, etc.), this research identifies four major social categories within the Latino community. Certainly, the Latino community is more than just a collection of people living in close proximity to one another. Linked by common heritage to Latin America, and especially Mexico, the community is connected by family and kin, sentiment and knowledge of history, self-help groups, artistic endeavors, social centers and cultural events. In other words, the community is a "constructed" space for the expression of cultural identity. The categories discussed in this paper, as adaptive responses to the surrounding social environment, transcend these institutional and cultural links and divide the community in ways that hinder political action. The four categories, which are based on strategies of engagement or disengagement with the larger domi- 
nant Anglo society are (1) a natal home orientation, (2) the gang organization, (3) enclave orientation, and (4) community activism. The failure of Latinos to mobilize their strength is not a consequence of culture or personality. Rather, different segments of the population have developed different strategies based on different perceptions, expectations, experiences, and needs. I suggest that these four adaptive strategies are useful for understanding the limited political mobilization of the local population.

\section{Aurora: An Ethnic Enclave}

With the loss of the Mexican-American war of 1848 , Mexican-Americans, or Chicanos, were created and viewed primarily as a "regional minority" (Saenz 1993). However since World War II and the various bracero programs Chicanos have dispersed beyond the southwest, moving especially to the upper mid-west. Chicago historically has been an important destination for those leaving the migrant agriculture stream. By $1970,7.3 \%$ of the city's population was Latino. Presently the city core is $24 \%$ Latino ( 450,000 people), and the surrounding metropolitan area is presently $14.5 \%$ Latino (1.1 million people). Although $75.5 \%$ lived in the core city districts in 1970 , this figure fell to $59 \%$ by 1995 with many moving into the suburbs (Chicago Tribune). Accompanying this rapid growth has been the concentration of the Latino population at the lower end of the social status scale in terms of income, poverty, residence, and education as they have penetrated predominantly white communities.

The mobilization of ethnic identity is a reaction to the continuing relative social isolation from the dominant ethnic group. At the same time various external structural pressures such as a split labor market and various discriminations in housing, education and employment confront the Latino community and force it to adapt either to mainstream capitalist-oriented consumer culture or turn inward and accentuate a Latinismo ideology. By Latinismo I mean a set of beliefs, ideas and perspectives based on shared cultural and historical experience and a system of values and norms which rejects Anglo consumer culture and embraces community, family, and heritage. To an extent, then, modern Latino identity is fabricated out of shared 


\section{Ethnic Studies Review Volume 22}

cultural and structural similarities in its confrontation with the larger white society. This confrontation is viewed in this paper from the perspective of Blauner's "internal colony," that is emphasis is placed on power and resource inequalities across racial lines. Blauner suggested that internal colonialism determines the asymmetrical relations of people of color within the dominant society. "Like European overseas colonialism," he wrote, "America has used African, Asian, Mexican, and to a lesser degree Indian workers for the cheapest labor, concentrating people of color in the most unskilled jobs, the least advanced sectors of the economy and the most industrially backward regions of the nation" (62). He identified several conditions to determine an internal colony: first, the degree of segregation, ethnic isolation, and restricted physical and social movement; second, the unequal access to resources and labor exploitation; third, cultural stigma, and fourth, limited political access. All of these conditions are found in the Aurora study area. These conditions make assimilation into the larger society a myth for blacks and Latinos because the colonial experience defines and embeds them in a system of racial domination. Nagel and Olzak differ somewhat from Blauner; but while recognizing power and inequality, they focus on ethnic identity and the ability to mobilize to compete for scarce social resources, that is, "Ethnic mobilization can be defined as the process by which a group organizes along ethnic lines in pursuit of group ends" (Nagel 96-97), usually in relation to attempts at the maintenance of the enclave by dominant outsiders. Following Blauner, Nagel, and Olzak, efforts at maintaining the enclave should encourage forms of ethnic mobilization to counter this structural position.

Portes and Manning have identified two general reactions to the attempt at permanent confinement of colonized ethnics. This condition has "given rise, in time, either to hopeless communities of 'unmeltable' ethnics or to militant minorities, conscious of a common identity and willing to support a collective strategy of self-defense" (Portes and Manning 49). In this paper mobilization-the willingness to support a collective strategy of self-defense-is considered problematic due to the identification of the four strategies employed to confront the marginality that colonialism entails. Several of these strategies 
tend to fracture the community by redirecting focus away from a community in solidarity to individual or group efforts that seem inimical to community mobilization as a basis of collective political power.

Portes and Manning characterize the Latin American presence in cities such as Aurora as immigrant enclaves. The immigrant enclave differs from Blauner's internal colony in that Blauner addresses a larger structural feature of society whereas Portes and Manning focus on structural features of the community. The difference between an enclave and colony is instructive. African American communities, if we follow Blauner's model, are colonies, while the Latino population in Aurora is an enclave. The central organizing feature of such an enclave is the local "indigenous" community economy controlled by members in the community. In African American communities much of the local business enterprise is owned by members of different outside ethnic groups-Whites, Koreans, South Asians, etc. The existence of an "independent" local minority economy is essential for understanding whether it is a true enclave or only a residential community. According to Portes and Manning, there are three conditions to being considered an ethnic enclave: a relatively large number of immigrants (mostly first generation and newly arrived) with the business experience to operate the economy; available sources of capital for investment, and sources of local labor for community businesses. Aurora represents a powerful model of an ethnic enclave. It has all the features of an internal colony-lack of political and institutional power, limited social mobility, alteration of indigenous culture, and geographic isolation-yet it is also a self-contained community with an indigenous economy providing most of what people need.

\section{Structural Conditions of the Aurora Barrio}

The social and political health of a community is dependent upon a number of factors including the educational attainment level of members, the school dropout rate, types of employment, and income distribution. The following briefly examines these factors that negatively impact on the Aurora community and represent the conditions over which the community must struggle. 
Aurora, a city of 99,580 people about 45 miles west of Chicago, has a Latino population of 22,864 (City of Aurora, 1995). Latin Americans have been present in Aurora since the arrival of the first Mexican families-Neves Acosta and Julia Padilla-in 1923-1924. During this early period, $50 \%$ of all Mexican immigrants were located in the city center around North Broadway, a pattern that presently continues, while numerous male railroad workers lived in make-shift railroad boxcars (Palmer 137). By 1930 ninety-six Mexicans were officially recognized residing in the city, $46 \%$ of who were recruited by and worked for the railroads (Palmer 203). Many others worked in the local bracero program. This population growth mirrored the same demographic trend in Chicago where the Mexican population increased from 500 to 20,000 between 1910 and 1930 (Gracia 185-207). A second wave of Mexican immigrants arrived during World War II to work in the local factories, supplementing the black and female industrial labor force.

\section{Population}

According to the most recent census, it is estimated that almost $30 \%$ of the Latino population in Aurora has arrived since 1980. As of 1990 , Mexican immigrants composed $86 \%$ of the Spanish speaking population followed by Puerto Ricans with 9 $\%$ (City of Aurora, 1995). Presently, Latinos, who make up between $25-27 \%$ of the city population, comprise the largest non-white ethnic community followed by African-American at $12 \%$. In essence, Aurora has two worlds-one Anglo and the other Latin/African-American. The map in Figure One shows the various census districts, highlighting the Latino areas. Notice the tight physical concentration of the population. To the north live predominantly Blacks and working class Whites while to the east and west are mostly white professionals. Until very recently the Fox River that runs through the city was the dividing line, a physical boundary between the Latino and white populations. Latinos have since moved to the west side, occupying the older working class neighborhoods located close to the river. The new boundary is less physical and more economical but real nonetheless. The communities on the west, along with the newer housing developments located to the 
east, are separated by the cost of housing. Within a half dozen blocks, the transition is made to newer, middle class homes which substantially increases purchase costs, a major impediment for Latino families. The Latino population therefore has expanded north and south-north into the older black and white neighborhoods and south into older white neighborhoods. Movement further east or west appears to be effectively blocked until such time that income opportunities improve.

According to Figure One, four census tracts are over $50 \%$ Latino and four tracts are home to between $30 \%$ and $50 \%$ Mexican and Puerto Rican peoples. Race and class limit the community's ability to expand. This has already led to a very tight housing market and overcrowded schools. For instance, an analysis of the housing availability by census tracts between 1980 and 1990 demonstrates housing conditions. If we compare census tracts more than $50 \%$ Latino (4 tracts,) with those more than $80 \%$ white (12 tracts), the trend in housing stock becomes apparent. Between the census years 1980 and 1990 , the four Latino dominated tracts lost an average of $7.5 \%$ of their housing stock while several tracts more than $80 \%$ white had an increase between $145 \%$ and $2353 \%$. Several white dominated tracts closer to the city center experienced a small decline in housing of 3\% (City of Aurora, 1991). As the inner city housing stock deteriorates due to the age of housing units (most build prior to or right after World War II), the income levels and ethnicity of community residents plays a factor in housing replacement. The housing "crunch" for Latinos is worse than is apparent due to the large numbers of undocumented people. Undocumented individuals are very difficult to account for when gathering statistics.

In general over $60 \%$ of the total Latino population of Aurora live within the confines of these eight tracts. A review of Table One gives the exact percentages of five Latino dominated tracts and compares them with predominantly white tracts. The heavily populated Latino tracts are found in the decaying city center of old industrial Aurora while the white populated tracts of Robert Reich's "symbolic analysts" (1992) are located east, south and west of the center in the emerging suburbs. 
Table One: Ethnic Percentages for Selected Census Tracts, 1990.

Tract Percent Latino Tract Percent Latino

$\begin{array}{llll}8534 & 72.0 & 8416 & 3.4 \\ 8535 & 50.7 & 8464 & 3.6 \\ 8536 & 54.8 & 8540 & 3.9 \\ 8538 & 50.5 & 8545 & 0.5 \\ 8541 & 35.4 & 8530 & 6.0\end{array}$

As mentioned, the Latino population is located predominantly in the several census tracts of the old industrial heart of the city bordering the Fox River. By 1970 the beginning of an ethnic enclave was apparent. In two central city tracts where the percent of lower-income households was between $60 \%$ and $90 \%$, the Mexican population had already reached more than $20 \%$ of the tract population (U.S. Census, 1970). As Latinos with lower incomes began moving in, "white flight" occurred, as Whites no longer maintained their property or converted to rental property. This led to neighborhood deterioration. The conclusion by Nelson \& Associates, "... that Aurora owners of housing in blocks newly penetrated by Negroes permit their properties to deteriorate" (43), not only applied to African-American residential movement but also applied to tracts penetrated by growing numbers of Latin Americans. By the late 1970 s the estimated poverty rate among Latinos had doubled to $15 \%$ of the population (compared to $6.9 \%$ for whites). Median housing values for 1980 (medium statistics are not available) tend to support this conclusion. The census tracts most heavily represented by Latin Americans had median housing values of $\$ 38,200$ while values in tracts almost exclusively white were $\$ 74,400$ (City of Aurora, 1995). White flight brought with it to the suburbs many city resources, neighborhood investment capital, and political power. By the mid1980 s white movement out to the surrounding areas was relatively complete. The more recent growth of newly settled white areas in the 1990s was due to the movement of middle class white professionals either out of Chicago or attracted to the growth of corporate services-headquarters, information, financial, and light manufacturing-in the suburbs. 
Nationwide Latinos are currently the fastest-growing sector of the U.S. population. Latinos, currently 22.8 million, are expected to be the largest nonwhite ethnic group by 2050 . This dynamic growth applies to Aurora as well but with the added feature of a general geographic shift in the ethnic population. According to the U.S. Special Census of Aurora in 1986, most of the city's growth has occurred on the eastside. While the near west side, predominantly white, had a slight population decline of $1 \%$, east of the river the population grew over $10 \%$ between 1980 and 1986 . Of the total city population the population proportion west of the river declined from $46 \%$ to $43 \%$ while east of the river the proportion grew from $54 \%$ to $57 \%$ between 1980 and 1986 (U.S. Special Census of Aurora, 1986). In terms of general population dynamics the city has seen an increase in population and most of this growth has been in the African-American and Latino communities. Recent estimates predict that Aurora's Latino population will reach 28,000 by the year 2000 . As indicated in Figure One, while the inner city has become increasingly non-white, the outer fringes have become increasingly white. As a reflection of this trend over the past decade a number of new school districts have developed around the city core to accommodate the perception that the Aurora schools are too heavily populated with black and Latino students, although such reservations are not expressed in terms of race but "proxies" such as the "quality of the schools."

The degree of cultural and structural assimilation is problematic at best. The degree of social-cultural isolation, a splitlabor market, physical concentration into a high-density Latin enclave, and the perception of discrimination suggests a marginalized community. The Latino community is very pronounced not just in numbers but also in terms of culture. A national survey conducted by Strategy Research Corporation supports this conclusion with nine out of ten Latinos identifying themselves as "very Latino," and the most likely to remain so ten years from now are linguistically isolated. In the significant eighteen to sixty-four-year-old category the number of respondents indicating that they spoke English poorly or not at all is over 30 percent (Northeastern Illinois Planning Commission 1993). This is significant because this age category is most 


\section{Ethnic Studies Review Volume 22}

active in terms of employment or social-political participation.

The degree of linguistic isolation has several dimensions. One is the pride Latinos feel in their heritage and their desire to maintain a social identity associated with the Spanish language. Second, the continual influx of new immigrants who are native Spanish speakers, estimated at over $20 \%$ in the 1990s, adds new ideas and cultural experiences fresh from Mexico to the general community population pool. And third, the degree of Spanish speaking media, Latino religious, charitable, and social services, and the commercial availability of Latino businesses and products in Chicago and surrounding cities like Aurora support the use of Spanish. Another factor is more paradoxical. Writing about border culture in EI Paso, Mario García recognizes the importance of maintaining one's culture. He writes, "... Mexicans preserved many native cultural traditions that aided them in their transition to a new American setting by providing a familiar cultural environment" (Takaki 72-81). The paradox is that this helps to encourage the ethnic enclave by constructing a greater approximation of Mexican natal social structure that may limit the necessity to accommodate Anglo culture. The consequence of an enclave for many is "acculturation" to the dominant culture rather than assimilation into it. That is, rather than give up their natal culture, Mexican-Americans negotiate a process of learning Anglo culture without sacrificing their own past. Rios writes, "They chose to accept a bilingual, bicultural mode of life rather than the monolingual, mono-cultural Anglo alternative" (141). The size and circumstance of the enclave, however, can mitigate even accommodation via a bicultural and bilingual mode of life by offering authentic ethnic services that can support isolation of community members, a conclusion supported by several informants.

Secondary structural assimilation, that is, access to an occupation within the power structure and the major social institutions, is limited for a number of reasons. In an earlier study of Spanish-speaking people in Chicago in the 1970s, Walton and Salces found the degree of political participation to be weak. "... Among the hundreds of elected representatives to various levels of government in the metropolitan area there are only four persons of Spanish heritage and these occupy 
relatively minor posts" (Padilla 57). For a variety of reasons Latinos in general are not active politically, although, as Yzaguirre correctly points out, voting equals power (179). Contemporary Aurora likewise fits this scenario of low political assimilation. Less than $10 \%$ of individuals of Latin descent work in city government, and only $20-25$ police officers of Latin descent work in a force of over 234 officers. All the aldermen and all but one city council member are white (one member is black) even in districts that are heavily Latino. It is only this year that the first Latino has been elected to any elected office in Aurora. The consequences of limited political participation are clear. "...Political influence-mere viability-determines who has access to services," writes Yzaguirre. "It is no surprise," he adds, "that politically active neighborhoods receive more police protection, more sewers...than less active ones" (179). Although discrimination is a constant presence, low levels of political organization and participation, education level, and the newness of many immigrants are contributing factors.

\section{Education}

Low levels of educational attainment, skill attainment, and recent arrival and entry into the labor force also operate to limit structural assimilation. A major contributing factor which supports not only ethnic isolation but also the split labor market is the educational system. Table Two illustrates the degree of educational attainment by the Latino population. Almost $48 \%$ of those twenty-five years and older have less than a ninth grade education followed by another $20 \%$ without their high school diploma. This compares to African Americans of whom $10 \%$ have less than nine years of education. White students by contrast have fewer dropouts and more students going on to advanced degrees. Of those twenty-five years and older, $21 \%$ of whites and $9 \%$ of Blacks have college or professional degrees compared to $4 \%$ for Latinos. As employment opportunities shift toward higher, more complex technologies, higher education becomes essential. The question is how do we account for the greater dropout rate among Latino students? A. Y. So believes that the most significant factor that relates to academic performance is socio-economic status (SES). 
Table Two: 1990 U.S. Census: Educational Attainment, 25 years and Older, by Race, for Aurora, in Percent.

$\begin{array}{lrrrrrrr} & & \begin{array}{c}\text { No H.S } \\ \text { Race }\end{array} & \begin{array}{c}\text { H.S. } \\ \text { Liploma } \\ \text { Diploma }\end{array} & \begin{array}{c}\text { Some } \\ \text { College }\end{array} & \begin{array}{c}\text { Assoc. } \\ \text { Degree }\end{array} & \begin{array}{l}\text { Grad } \\ \text { B.A. Prof. }\end{array} \\ \text { White } & 9.5 & 13.4 & 29.7 & 20.1 & 6.1 & 4.6 & 6.6 \\ \text { Black } & 10.1 & 27.5 & 28.8 & 18.9 & 5.3 & 6.2 & 3.2 \\ \text { Latin } & 47.8 & 21.3 & 15.3 & 9.0 & 2.3 & 3.0 & 1.3\end{array}$

So reports that if one removes the effects of SES on students, differences in performance level tends to diminish (23970). Perez, on the other hand, believes that the low educational attainment level of Latinos relates to a number of factors including immigrant status, language background, school personnel, and social adjustment, among others (35). The importance of Perez's insight is that knowledge, skills, and cultural styles are forms of capital that translate into economic success, and low educational attainment can lead, along with discrimination, to the limited economic mobility of the Latino community.

As a consequence of the growing minority population in Aurora, the Aurora school system has seen a dramatic growth in the ethnic student population. School District 131 is the central city district encompassing the Latino community, while 129 is an ethnically diverse district in a period of uncertain transition. District 204 lies on the east side of Aurora within a ring of new middle-class and primarily white housing developments. To the south and far-west of the city are several other and newer school districts which are almost exclusively white and whose districts were drawn to keep those students out of Aurora's schools.

Table Three: Aurora School Districts by Ethnicity, Language, Low-income, 1993 and 1994, in Percent. School District White Black Latino Proficiency $\begin{gathered}\text { Limited } \\ \text { Panguage }\end{gathered}$ Low

$\begin{array}{lrrrrr}31 \text { East } & 28.8 & 20.4 & 49.8 & 25.4 & 52.3 \\ \text { 129 West } & 55.6 & 19.7 & 22.7 & 4.2 & 30.5 \\ \text { 204 Indian Prairie } & 86.7 & 5.3 & 2.4 & .9 & 1.7\end{array}$


Tables Three and Four illustrate the ethnic composition of the three major Aurora school districts. The central and closest district to the Latino community is district 131 . The average composition of Latino students is almost $50 \%$. Five schools are over $60 \%$ Latino and L.D. Brady elementary school has a Latino population of $93.7 \%$. In several 131 schools, the white student body is under $8 \%$. As seen in the tables, there is a relationship between the degree of school ethnicity, language proficiency, and income. The east schools average $52 \%$ of the population from low-income homes. The number of students from low-income homes is instructive because it suggests a lower property tax base for school funding. There appears to be a correlation between ethnicity of the east and west high schools and faculty salaries. The average Aurora East High School salary is $\$ 34,469$ in 1993 and $\$ 41,540$ for Aurora West in 1994. Teachers at East, where the student body is over $49 \%$ Latino and $20 \%$ Black, earn only $83 \%$ of the salaries at West High School. This apparent discrimination goes beyond the physical infrastructure to include per pupil spending, teacher compensation, and school board representation. Following the internal colony model in which dominant whites continue a colonial system of control, it was only last year a Latino was elected to the school board in the predominantly Latino Aurora East 131 School District. Table Three provides specific data for several district 131 and 204 schools and clearly illustrates the degree of student segregation.

While the schools selected in Table Four are the extremes of ethnic segregation, they do illustrate the degree of concentration of Latino students. The increase in a Latino presence is accompanied by a significant increase in low-income students and students with limited language proficiency in English. The table illustrates not only the growth of the Latino school population for select schools in Aurora but also implies the kinds of problems these schools face. L.D. Brady School of District 131 shows the growth of the Latino student population from 1989 to 1993. The growth in the number of students with limited English language proficiency has grown by $57 \%$ and the percentage of students coming from low-income families by $138 \%$. At the opposite end is District 204 Wheatland that has seen only a marginal increase in the non-white population. The con- 
centration of low- income students presents special problems and demands special resources for District 131 schools. This results in the diversion of scarce school funds to special education and ESL classes. According to one informant, in schools with growing Latino populations such diversion of school resources can be a cause of friction with Whites questioning the validity of such reallocation. The Indian Prairie School is completely the opposite with a student body almost exclusively white and middle class. It is interesting to note that on the west side is one large school district (129) while on the east are two: the older 131 district and the new 204 district. The informant suggested that the new district was developed to prevent the mobility of Latino students from enrolling in the newer, white schools (DM, personal communication). Apparently students can move within a district but not between them. As the figures in Table Four indicate, the two middle schools on the near west side in district 129 are experiencing a transition toward a more ethnic student body as families attempt to break out of the barrio. For the 1994-1995 school years, there has been an average decline of 14.6 in the white student population compared to an average $17.5 \%$ and $25.1 \%$ increase in the African American and Latino populations respectively. For the twelve schools of District 129 the overall trend is a decline of $5 \%$ in the white student population with Blacks increasing their representation by $8 \%$ and Latinos by $4.5 \%$ (City of Aurora 1995)

\section{Table Four: Select Aurora Elementary and Middle Schools for 1989, 1990, 1993-1995, in Percent.}

\begin{tabular}{|c|c|c|c|c|c|}
\hline School & \multicolumn{3}{|c|}{ Ethnicity } & $\begin{array}{l}\text { Limited } \\
\text { Language } \\
\text { Proficiency }\end{array}$ & $\begin{array}{l}\text { Low } \\
\text { Incom }\end{array}$ \\
\hline \multicolumn{6}{|c|}{ ㄴ. D. Brady (\#131) } \\
\hline 1989 & & 6.2 & 86.5 & 41.9 & 33.1 \\
\hline 1990 & 7.4 & 7.0 & 85.4 & 53.2 & 39.7 \\
\hline 1993 & 4.4 & 1.9 & 93.7 & 66.0 & 79.1 \\
\hline \multicolumn{6}{|c|}{ Wheatland (\#204) } \\
\hline 1993 & 94.6 & 1.4 & 0.7 & 0.0 & 0.5 \\
\hline 1995 & 92.5 & 2.2 & 1.5 & 0.7 & 0.7 \\
\hline
\end{tabular}


Schneider (\#129)

$\begin{array}{llllll}1994 & 64.5 & 16.4 & 12.0 & 0.5 & 31.4 \\ 1995 & 56.7 & 20.8 & 15.1 & 2.0 & 37.1\end{array}$

Greenman (\#129)

$\begin{array}{llllll}1994 & 67.0 & 16.7 & 16.1 & 0.3 & 38.8 \\ 1995 & 57.6 & 19.2 & 22.4 & 2.3 & 39.8\end{array}$

The two factors contributing to the demographic shift are the crowded eastside schools and a residential shift across the river as the Latin community responds to a very tight housing market. The implications for many west schools are clear. As a school's ethnic composition shifts toward a non-white student body, white flight increases. When viewing Figure One it is clear that Latinos are highly concentrated in central city schools while low representation is found in the outlying areas. These outlying areas are generally new housing developments which cater to the professional middle class. Students can attend schools within the school district determined by their residence, which in turn is determined by income. The new form of discrimination appears to be based more on class than race. In this case, then, class is a proxy for racial segregation.

These tables suggest that schools with the heaviest Latino (and African-American) student populations are those schools with the greatest degree of social problems based on language and poverty and also ethnic isolation. Brady Elementary is over $95 \%$ non-white while Todd is $64 \%$. These schools have witnessed an increase in non-educational social problems with which they must contend, while at the same time they have received a relatively smaller share of educational revenues. If schools are to prepare students with skills for higher education and new high-tech jobs, as well as a greater degree of ethnic integration in the broader political and social community, then District 131 schools, and to a lesser extent District 129, are key to maintaining or breaking out of Blauner's internal colonialism of marginalization and isolation.

\section{Labor Markets and Income Distribution}

Understanding the relationship between education, income distribution, and labor market participation is necessary 


\section{Ethnic Studies Review Volume 22}

for understanding the Aurora community. Much research on Latino income distribution relative to Whites has focused on one of two questions. Are differences in income earnings an outcome of degree of human capital (such as education) or the existence of discrimination? Considering the age distribution and the recent arrival of large segments of the population, both questions are pertinent.

What appears apparent from this table and the following tables is the relationship between education and income. The 1990 U.S. census estimates that over $16 \%$ of the Latino population are below the poverty level, an increase of $8 \%$ since 1970 (Northeastern Illinois Planning Commission 1993). This is a biased figure since, as one informant estimated, over $30 \%$ of the population are undocumented aliens, and these individuals do not apply for welfare aid or unemployment nor are they likely to be accounted for in the census. Yet the undocumented worker, I suspect, earns only a little above the minimum wage, if lucky. While exact figures are not available, the poverty level may be closer to $20-25 \%$ of the community even though figures that are more recent place the unemployment rate at about $5 \%$. The unemployment rate, however, is a poor proxy for estimating poverty. The problem is not one of unemployment versus employment but rather the low pay rate of much of the work available, especially for undocumented workers. Nevertheless, low-income students concentrated in poorer schools and faced with various discriminations tend to drop out at greater frequencies than other students.

However, analysis of where Latinos are working suggests a segmented labor market where Latinos are directed into low wage employment. According to Bonacich recent immigrants or ethnic groups from rural areas ordinarily make up a source of readily available cheap labor (1972). Meléndez suggests that "wage inequality could be attributed to barriers that prevent Hispanics access to good jobs" (192; 195-98). The importance of ethnicity for the labor market is determined not only by the structure of local employment availability (i.e., kinds of work available) but also due to employers' perception of the ethnic characteristics of the community (that could lead to discriminatory hiring practices). These groups provide a pool of cheap and often pliable labor but also represent a threat to the Anglo 
labor force that traditionally has occupied these low-level manufacturing positions.

In Aurora the Latino labor force is broken into both primary and secondary segments. The primary segment is manufacturing, assembly line, and construction, and the secondary segment are such services as lawn and garden service, restaurant service, and retail supply stocking. Lawn and garden and restaurant services are almost exclusively a Latino reserve throughout Kane and Dupage counties. A rough estimate suggests that about $80-85 \%$ of all lawn senvice is Latino, including supervisory positions. It is interesting to note that there is a segmented labor market in the lawn care industry as well. Most of the private lawn care companies are composed of Latino workers who primarily work around community developments and corporate campuses. These jobs are low wage, have few benefits, if any, and are seasonal at best. However, those employees working for the county who do road work and maintenance are mostly white. These are year-round county government jobs with benefits and higher pay.

Table Five indicates the distribution of employed Latinos over the age of sixteen for those living in census tracts most heavily Latino. While only $6 \%$ of the Latino labor force work in agriculture and construction, they represent $17 \%$ of all laborers in that sector compared to $2 \%$ for Whites. Many of these jobs involve low-skilled construction work and manual labor road repair work. In tract $A$ districts an average of $47 \%$ of the labor force is in manufacturing and an additional $16 \%$ in wholesale/retail trade. This compares to select white dominated tracts where only $8 \%$ of the labor force are in manufacturing and $22 \%$ in wholesale/retail. The relatively high number of Latinos in the wholesale/retail business is attributed to size and isolation of the ethnic enclave. Conversely, only $10 \%$ of Latinos are employed in professional services and public administration whereas among Whites the figure is $24 \%$. Fewer than $2 \%$ of Latinos are in public service while for Whites it is almost $5 \%$. Clearly, the white population is experiencing a transition from a blue-collar labor force to a professional labor force while Latinos remain concentrated in the more traditional labor areas. These figures tend to support national statistics that indicate that $11 \%$ of Mexican Americans are in profession- 


\section{Ethnic Studies Review Volume 22}

al positions compared to $30 \%$ for white Americans (Feagin and Feagin 1996). Apparently, for whatever reason-education, recent arrival-Latinos are funneled into the sort of jobs most members of the dominant group do not want. Most of the antagonism Latinos face in Aurora comes from working class Whites who compete with Latinos for a limited and declining number of blue-collar jobs. Since upper class Whites are not in direct competition for employment, resources or education, Whites feel only a cultural threat to the ethnic composition of shifting demographics.

Table Five: 1990 U.S. Census: Employed Latin American Persons 16 Years and Over by Industry and Census Tract, in Percent.

Ag. \& Transprt. Whlsl. Ret. Pub. Prof. Pub. Tract $A^{*}$ Total Cons. \& Comm. Man. Trade Serv. Serv. Adm.

$\begin{array}{lllllllll}8534 & 100 & 6 & 4 & 47 & 16 & 16 & 8 & 1 \\ 8535 & 100 & 4 & 4 & 51 & 15 & 11 & 13 & 2 \\ 8536 & 100 & 7 & 5 & 46 & 16 & 17 & 7 & 2 \\ 8538 & 100 & 7 & 4 & 42 & 18 & 13 & 14 & 2\end{array}$

Tract $\mathrm{B}^{\star \star}$

$\begin{array}{lrlrrrrrr}8465.1 & 100 & 5 & 11 & 17 & 23 & 22 & 19 & 3 \\ 8530.3 & 100 & 6 & 8 & 22 & 21 & 16 & 24 & 5 \\ 8530.2 & 100 & 5 & 7 & 28 & 21 & 14 & 19 & 4 \\ 8539 & 100 & 7 & 4 & 16 & 16 & 18 & 32 & 6\end{array}$

${ }^{*}$ Tract $A$ is census tracts with over $50 \%$ of the population of Latin American ethnicity

${ }^{\star *}$ Tract $B$ is census tracts between 4 and $11 \%$ of the population of Latin American ethnicity

The distribution of household income is correlated with the unequal distribution in employment and the lower education achievement levels. With a majority of Latinos found in lowerskilled positions requiring less education their income distribution tends to be skewed downward. On the other hand, according to Table Six, Whites tend to occupy a greater proportion of positions requiring higher education and thus command higher incomes. Almost $47 \%$ of all Latinos in the work- 
force earn under $\$ 25,000$ a year and only about $4 \%$ earn incomes over $\$ 75,000$. Whites compare with less than $11 \%$ earning under $\$ 25,000$ and $20 \%$ earning more than $\$ 75,000$. Overall, average household incomes for Latinos are only $86 \%$ of white income. When broken down into per capita income the gap is even wider: Latinos had a per capita income of $\$ 7,938$ in 1990 while Whites had $\$ 13,335$ in 1990. In per capita terms, Latinos earned only $59 \%$ of white income. Finally, the ethnic enclave itself provides substantial employment. The enclave is large and diverse in business to the extent that there is considerable internal demand for labor. Latino community employment tends to be in the wholesale and retail trades where Spanish language proficiency and familiarity with Mexican products and customer interaction is important. Found within the community are a variety of Latin (mostly Mexican American) oriented services such as travel agencies, real estate agencies, automobile sales and repair, hairs alons, grocers, numerous vendedoras ambulantes, and clothing stores.

\section{Table Six: 1989 Household Income Distribution for Selected Census Tracts, in Percent.}

Latino

Income

$\begin{array}{lrrrr}\$-10,000 & 13 & 12 & 23 & 9 \\ 10-25,000 & 32 & 30 & 34 & 35 \\ 25-49,999 & 41 & 40 & 31 & 38 \\ 50-74,999 & 10 & 13 & 10 & 14 \\ 75-149,999 & 4 & 5 & 2 & 4 \\ 150,000+ & 0 & 0 & 0 & 0\end{array}$

White

8416846485408530

\section{Communities of Resistance and Disengagement}

The exposure of the Latino community to new ideas, values, norms, and institutions has forced it to confront a sense of deprivation, loss, and vulnerability. For many, writes Padilla of Chicago, "integration has come to mean relegation to economically less productive and increasingly marginal positions in the urban labor force" (7). Of interest here is how the community has reacted to this situation. As Padilla argues, "... the degree 
of integration of an ethnic group in the institutional life of the larger society determines, in part, the kinds of strategies or cultural innovations that such a group would create to relate to circumstances of society inequality" (6). Four strategies are identified in Aurora which suggest a community of "resistance" and "disengagement" to the various forms of inequality. The four strategies are (1) a natal home orientation, (2) gang organization, (3) enclave orientation, and (4) community activism. In general we can conceptualize the natal home orientation and enclave orientation as strategies of disengagement. Rather than assimilate the goal is to construct a more "authentic" Latino experience within the Latin community and along with withdrawing from most forms of inter-ethnic interaction. Community activism and gang organization, on the other hand, represent strategies of resistance, one "negative" and the other "positive." Community activists operate from an ideological understanding of the need to further open up the white dominated political economy. Activists, some of whom often share an enclave orientation, are those most likely to structurally assimilate and culturally "accommodate" while at the same time promoting ethnic pride, self-identity, and political response.

(1) Natal home orientation-these are individuals, illegal or legal, who believe residence in Aurora (and the US) is temporary and that sooner or later they will return to Mexico and Latin America. Kearney (1995) refers to these people as "transnationals." "Transmigrants are immigrants whose daily lives depend on multiple and constant interconnections across international borders and whose public identities are configured in relationship to more than one nation-state," according to Glick Schiller, et al (48). These individuals maintain a dual existence with a predominant strategy or orientation of "disengagement." They have little interest in investing in community activism to promote social change-they are only visitors, even if they have U.S. citizenship and will eventually return home. Many remain in close contact with their natal village, sending money, owning property, and maintaining village membership through visitations. Residence in the U.S. is an economic strategy rather than any sort of "lifestyle" commitment, especially in light of perceived white antagonism. One informant in particular has 
been in Aurora for nineteen years yet returns to Mexico every year and recently bought a piece of land in preparation for moving back. He felt that after nineteen years he remains a stranger in this country, rarely venturing out into the Anglo world and mixing with whites, although grateful for the opportunities it has given him.

(2) Gang organization-these are younger people, generally but not exclusively male, who react to their social environment through gang activity. It is estimated that at least eight gangs operated in Aurora in 1996 with an estimated membership of over 700 individuals (The Beacon News). The high ethnic concentration of low-income people and the poor quality of public schools has led to a sense of frustration, anger, and resignation. Gang members are aware of their marginal status on the ethnic stratification ladder. The inadequate assistance the city provides to the community, the limited degree of job availability, lack of recreational outlets, discrimination, and the dysfunctional homes born of poverty and limited opportunity have a negative effect upon many young Latinos' perception of the future. Furthermore, according to one informant, gang members are aware, that "they are not wanted, that whites don't understand or care for 'Mexicans."' They are cognizant of real boundaries separating them from white ethnic communities that are essentially "foreign" territory. Gang membership is a form of negative resistance in the sense that gangs confront the broader political economy but have no theoretical basis for understanding the structural and operational makeup of a system that systematically engages in racism, discrimination and ethnic isolation. The only avenue for venting frustration and anger are those within reach-each other.

A variety of reasons look beyond deviance as to why youth join a gang. Cloward and Ohlin suggest that gang membership is attractive in light of counter conditions of unemployment and scarce income opportunities (1960). In Aurora 18\% of those in the prime gang age group, twelve to seventeen-years-old, are living below the poverty level. If we include the broad age category, eighteen to sixty-four, the number living below the poverty level increases to $36.1 \%$ (1990 US Census, Summary Tape File 3). Twenty-eight percent of all Latin males are either unemployed or have quit looking for work (1990 US Census). 


\section{Ethnic Studies Review Volume 22}

Clearly, gang membership with its associated control over various illegal economic activities-drugs, stolen goods-offers an alternative to unemployment and poverty. In 1996 police seized an estimated $\$ 7.7$ million in drugs indicating significant income opportunity (The Beacon News). Crime in association with gang organization appears pervasive. The EnglishSpanish newspaper, El Conquistador, stated: "The people of Aurora are worried about gang violence and drug use. Several murders have already been committed in the first month of 1996. A record high of twenty-five homicides in Aurora in 1995 has intensified the fear throughout the community".

On the other hand researchers such as James Diego Vigil stress that many become gang members in search of a sense of la familia in a world surrounded by Anglos, a place where they don't feel rejected. Joy Brown, et al., reports the following conversation with "Eddie," an eighteen-year-old (34-35).

Q: "Why is it difficult living here? Do you miss home?" (He has been in Aurora four years.)

A: "The United States in not like I thought it would be. I feel lonely a lot."

Q: "Why do you feel lonely?"

A: "Not being able to speak [English] well and feeling rejection."

Q: "Rejection from who?"

A: "White people. It is difficult for them [young Latinos] to be here, to adjust living here. They feel like strangers."

Gang membership not only can compensate for socioeconomic deprivation but also can provide the means for maintaining cultural and personal identity to counter such feelings. Gangs can provide status and a sense of belonging that many young Latinos find deficient in the community and broader society.

(3) Enclave orientation-individuals in this group may be either legal or undocumented residents. Here the operant characterization is one of rejection of dominant Anglo values and institutional means and/or social disengagement. Aware of their hostile environment or indifferent to it, this group, supported by an ideology of Latinismo, chooses to limit their interactions with the broader outside society. The characteristic of 
this group is an intentional but general isolation from Anglo society around them. In part as Mexicans have moved into Aurora they have recreated the world left behind-the ethnic enclave. Rois has observed, "Cultural elements which synthesized the Mexicano Mestizo were not left behind by Mexican migrants coming north. Language, food, customs, religion, art, music, folklore, and medicine were brought from all parts of Mexico to the United States" (140). English comprehension is limited or non-existent, and physical movement is usually local unless accompanied by someone else. For members of this group shopping is exclusively in the Aurora Latino community (there are three or four major supermercados). Newspaper reading is confined to the two local Spanish language newspapers. Institutional interaction such as PTAs, political activity, and libraries, is very limited with people often relying on their children to mediate. Immigration can be broken down further into two groups. One is comprised of the recent immigrant new to the U.S: young but with limited language and occupational skills. The second group, generally older, has followed families to Aurora and have limited need to move beyond their local community. For example at a Cinco de Mayo fiesta last year I met several older Mexican women who, after following their families north, have lived in the community for a number of years yet essentially speak no English. There even exist several curanderos and herbal shops.

Because they are both acts of disengagement, there is an overlap between natal home and enclave orientations. There are, however, several differences. Many who share the natal home perspective also work and interact outside the enclave. Even though many will eventually return to Mexico, until that time they attempt various negotiations with the broader community. Many, for instance, work in factories, stockrooms, and restaurants in predominantly white communities. While possibly limited, they do interact with whites. Those remaining isolated within the Latino community are generally older or those newly arrived. Many of the recently arrived are younger and most will eventually seek outside opportunities after a period of acclimation.

(4) Community activism-according to Navarro, competent and committed leadership is an essential component for 
any community organization . "Leaders must be multi-functional" informs Navarro. "They are motivators of the people,visionaries who inspire hope and ideas, mechanics of organization, and strategists who plot and carry out the change" (362). In Aurora this is a relatively small group of mostly university-educated, though not necessarily so, individuals who through social service agencies, churches, community centers, and outreach programs mediate between the Latino community and the larger Anglo-dominant social and political structures. This group in general has the ideological consciousness and awareness of the meaning and intent of systematic discrimination and also has the ability to confront the social-political structure and mediate in the name of the Latin community.

Community activists can be broken into three groups: grassroots organizations such as the Latino Empowerment Project; those who work as social service providers such as Mutual Ground; and those "institutional" in character such as the Hispanic Chamber of Commerce, the editor of El Conquistador, teachers and political officials. All three groups tend to have different agendas and, as in the case of the Chamber and several grassroots organizations, they also have serious disagreements over strategy and outcome.

One major institutional presence in the Latino community is the church. While it is difficult to assess the power and impact of the church, especially the Catholic Church, there are a number of Latin American churches operating in Aurora. One informant, José, is a pastor as well as community activist employing a liberation theological approach to his congregation and the Latin community in general. According to his perspective, his mission is to move beyond addressing the needs of "Americanization" to the issues of social justice and community building. José's masses tend to accentuate moral responsibility, traditional values, and the need for solidarity. His church and others have become places of refuge for the newly arrived as well as focal points for institutional support for solving community problems.

Activists are a crucial element in community mobilization for development. Community activists include members of the Hispanic Chamber of Commerce, El Centro Panamericano, 
Joel Perez's God's Gym, and the Root Street Community Resource Center. Agencies such as the Favala Foundation and El Centro Panamericano offer and promote various social services. Meléndez's research on development in Latino enclaves supports this perspective, concluding that "These cases show that effective strategies depend on both the mobilization of leadership and other resources internal to the community and their articulation to those mainstream economic institutions that ultimately provide access to jobs and financial resources for residents and businesses" (126).

A small number of Latino professionals are active in developing political strategies such as voter registration drives. Second but less "pro-active" groups are those community members, possibly less educated but equally concerned, who attend meetings and public forums to support the activities of the mediators. Political participation is limited by either the legal status of the voter (you must become a naturalized citizen to vote) or the low median age of the Latino population (Feagin and Feagin). As Gonzalo Arroyo, the director of Family Focus Aurora, observes, "The problem here is not discrimination but participation" (Chicago Tribune). One informant who works for a local community agency believes that the reason for such low political and community participation is fear. Many undocumented individuals are fearful of becoming too visible and located by the INS. Another reason suggested is the parochial and unorganized nature of those in leadership positions. Most sociologists would add that political participation, outside of compelling perceived threat to community members, is predicated on class background (Neighbor 10). Certainly educational level, income, and occupation are significant elements in the motivation for political participation.

\section{Conclusion}

Aurora is, as Richard Rodriguez once characterized Los Angles, a city of separate lives. The Anglo city lies west of the Fox River and on the east side resides the "other," black and Latino. The Latino community is dynamic with numerous Latino owned businesses and services, street vendors, and a variety of celebrations. The summer months are a time of numerous family activities such as qinceañeras, school gradu- 


\section{Ethnic Studies Review Volume 22}

ation parties, and fiestas sponsored by local churches. All of these help to strengthen ethnic pride, cultural identity, and promote a sense of cultural community. At the cultural level the Aurora barrio exhibits a strong sense of ethnic solidarity.

Aurora is also a city of impending crisis. Due to the forces of economic globalization Aurora is experiencing transformation. Unlike previous periods entry-level industrial jobs that historically have provided a better standard of living are rapidly declining. While the issue of transformation is difficult to address at the international level, an alternative is found at the local level. Without greater active political participation as an ethnic group it is undecided whether the city will develop policies and devote resources to deal with deteriorating housing stock, unemployment, crime, and discrimination. Without effective public policy the issues of affordable housing availability, public school retention and graduation, and employment opportunities in the Latino community will remain serious. While there has been success in both physical and socio-economic mobility, the success rate has not been enough to off-set the influx of new immigrants or the resident working poor.

The problem of limited political response is not located in various Latino groups' fear of loss of cultural identity by engaging the broader political or cultural communities. Most of Aurora's Latin population is Mexican with a strong sense of heritage and shared historical experience. Engagement therefore represents no threat to ethnic cultural boundaries. As Padilla points out, most ethnic groups in Chicago have "turned to their ethnicity as a strategic solution to their conditions in urban America" (142). Meléndez agrees and suggests that since poverty is usually over-represented in ethnic areas, "ethnic and racial solidarity can have an important impact on city development strategies" (111). Yet unlike Padilla's experience in Chicago, Aurora has been limited in its ability to mobilize Latinismo as a strategic resource with which to confront the political establishment. Due to the twin factors of low-income and the fluid movement of Latinos across national borders, on the national level Latinos have historically had very low levels of political participation (de la Garza). Beyond the well-established observation that the poor do not participate politically, a major impediment to mobilization in Aurora is the number of 
undocumented workers in the community. In a recent study Rob Paral estimates that $44 \%$ of the undocumented in Illinois are from Mexico (5). Their potential as a political force is attenuated by their fear of La Migra (the Immigration and Naturalization Service) and deportation. The outcome of these forces is a poorly developed political constituency.

The natal home and internal orientations of disengagement are individualist in adjustment and thus cannot act as a resource for political action. Gang organization, while pursuing a collective orientation and one of engagement, is located within perceived deviant behavior and is thus not very useful as a resource for operation. Only community activism has the potential to be a consolidating resource for action but is limited in terms of numbers and limited over-arching political vision which engages both the local community and the broader political community. During the 1970s, the Chicano Movement (such the Movimiento Estudiantil Chicano de Aztlán and the Mexican American Political Association), as a broad nationallybased civil rights movement and ideology, lent encouragement and support to community organizing (see Navarro's case study of the community of Cristal in South Texas). At present, local action in Aurora is not linked to any broader ideological or political movement to help articulate community issues and support organization. However, the articulation of a political ideology should be a major goal of community leadership. Ideology "delineates the movement's direction, symbolism, justification, and strategy" (Navarro 365). The potential for mobilization is there (in terms of issues to confront, population density, a limited but experienced leadership, etc.), but according to my informants there is no over-riding issue around which community members can coalesce.

Social solidarity is all the more important due to the structural changes in the U.S. economy, the low retention rate of Latino high school youth, and the sharp cut-backs in social service programs to aid low income people. It is apparent that the resources to confront the issues of poverty and isolation must come from the community itself. But in the present era of economic structural change a major issue is employment. Based on his research in San Antonio, Texas, Jorge Chapa agrees with this assessment. "Any useful policy discussion," 


\section{Ethnic Studies Review Volume 22}

he writes, "must address the question of how low-wage, lowskilled workers can earn a decent living. Today, many Latinos are poor because they work in low-wage jobs" (82). It is safe to assume that the industrial employment structure that allowed many groups to experience social mobility is gone and will not return. The problem becomes one of outlining where the possible solutions lie.

Since the labor market structure works against the community as a strategy for mobility, other alternatives must be sought. It appears that greater educational attainment, job retaining, and political mobilization are the only viable solutions. This has two implications. One, influence over city policy can redirect greater educational resources toward retention and increase the chances of Latinos graduating to go on for further education and training. The second implication is at the ideological level of representation. Community leadership must likewise challenge traditional definitions of Latinos. Marta Tienda writes that, "The significance of ethnicity for the labor market stratification... depends not only on local employment conditions but also on how individual ethnic traits circumscribe choices, how ethic traits are evaluated in the marketplace...." (262). In other words prevailing stereotypes and explanations of Latinos must be confronted and challenged. The dominant ethnic group must see Latinos as a resource rather than as a problem; that is, the future of Aurora is intertwined with the future of Latinos. The challenge of Latino leadership is to develop an ideology around which effective organization can develop. Latinos offer more than just increasing numbers. They offer, Yzarguirre concludes, "values related to family, hard work, and patriotism, among others, [that] help unify all communities" (184). But these values must be articulated and included in a greater, more inclusive political ideology.

The lesson from the Cristal, Texas, experience is that "even if an ethnic group constitutes a majority and achieves community control of a city council, school board, or county, mere election to office does not resolve the many problems they face" (Navarro 374). The challenge of Latino leadership is to develop an ideology around which effective organization can develop. However, the ideology must not only motivate the barrio to action but must likewise articulate to the broader 
community the meaning and importance of such action. Even though the Latino population is growing, as it is throughout the U.S. and Illinois, the experience from Aurora suggests that population number or density is not enough for effective inclusion in the political process. As this paper makes clear, educational attainment in terms of high school retention and skills development that lead to post-secondary education is paramount. Education plays two key roles for an ethnic community such as Aurora. First, it is a key factor in adapting to the changing needs of the labor market for income mobility, and second, for developing an understanding of the political process and possible strategies of engagement. Additionally the ability of an ethnic group to influence or to design and implement public policy may be dependent upon developing alliances with the broader, non-Latino community, especially other minorities. These coalitions are necessary to overcome political and social isolation that has been present in the community since its founding. The future, then, is clear-solidarity must be found from within and alliances and coalitions developed without.

\section{WORKS CITED}

"Tale of Two Cities and Their Gangs," The Beacon-News (March), 1996.

Blauner, Robert. Racial Oppression in America. New York: Harper \& Row, 1972.

Bonacich, Edna, "A Theory of Ethnic Antagonism: The Split Labor Market." American Sociological Review (1972) 37: 547559.

Brown, Joy, et al. "A Snapshot of Latin American Youth at St. Nicolas Catholic Church in Aurora, IL." Unpublished manuscript, Wheaton College, Wheaton, IL, 1996.

Chapa, Jorge. "The Burden of Interdependence: Demographic, 


\section{Ethnic Studies Review Volume 22}

Economic, and Social Prospects for Latinos in the Reconfigured U.S. Economy." Frank Bonilla, et al., (eds.). Borderless Borders: U.S. Latinos, Latin Americans, and the Paradox of Interdependence. Philadelphia: Temple University Press, 1998.

"The Next Wave." The Chicago Tribune (15 March 1998, Sec. 17). p. $1,7$.

City of Aurora. "1990 Special Census of Aurora, Illinois." Planning Division, Community Development Department, Aurora, IL.' 1995.

Housing Summary." Planning Division, Community Development Department, Aurora, IL., 1995

"1993-95 Report Card." Aurora Schools District Administration Office, Aurora, IL., 1995.

"U.S. Special Census of Aurora."

Planning Division, Community Development Department, Aurora, IL., 1986.

Cloward, Richard, and Lloyd B. Ohlin. Delinquency and Opportunity: A Theory of Delinquent Gangs. New York: Free Press, 1960.

de la Garza, Rudolph. "Mexican-American Voters: A Responsible Electorate." Pp. 63-67 in Frank Baird, (ed.). Mexican Americans: Political Power, Influence or Resource. Lubbock: Texas Technical University Press, 1977.

El Conquistador. February 1. 1996. Aurora, Illinois.

García, Mario T. "Border Culture." Ronald Takaki, (ed.). From Different Shores: Perspectives on Race and Ethnicity in America. New York: Oxford University Press, 1994.

Glick Schiller, Nina, Linda Basch, and Cristina Szanton Blanc. "From Immigrant to Transmigrant: Theorizing Transnational 
Migration." Anthropology Quarterly 68:49-63.

Gracia, Gerardo Necoechea. "Customs and Resistance: Mexican Immigrants in Chicago, 1910-1930." John Hart (ed.). Border Crossing: Mexican and Mexican-American Workers. Wilmington: Scholarly Books, 1998.

Kearney, M. "The Local and the Global: The Anthropology of Globalization and Transnationalism." Annual Review of Anthropology 4 (1995):547-65.

Kent, Noel J. "A Stacked Deck: Racial Minorities and the New American Political Economy." Young I. Song and Eugene C. Kim (eds.). American Mosaic: Selected Readings On America's Multicultural Heritage. Englewood Cliffs: Prentice Hall, 1993.

Kraig, Glen M. "A Study Comparing the Differences in the levels of Achievement of Tenth Grade Anglo and Hispanic Students in One and Two Parent Homes." Young I. Song and Eugene C. Kim (eds.). American Mosaic: Selected Readings On America's Multicultural Heritage. Englewood Cliffs: Prentice Hall, 1993.

Martínez, Ruben. "Beyond Borders: Culture, Movement and Bedlam on Both Sides of theRio Grande." NACLA: Report on the Americans 30 (1995): 36-39.

Meléndez, Edwin. "The Economic Development of El Barrio." Frank Bonilla, et al. (eds.). Borderless Borders: U.S. Latinos, Latin Americans, and the Paradox of Interdependence. Philadelphia: Temple University Press, 1998.

Nagel, Joane and Susan Olzak. Competitive Ethnic Relations. New York: Academic Press, 1986.

Navarro, Armondo. The Cristal Experiment: $A$ Chicano Struggle for Community Control. Madison: University of Wisconsin Press, 1998.

Neighbor, Howard D. "Latino Political Participation in a 


\section{Ethnic Studies Review Volume 22}

Bicultural Setting." Roberto E. Villarreal and Norma G. Hernandez (eds.). Latinos and Political Coalitions: Political Empowerment for the 1990s. New York: Greenwood Press, 1991.

Northeastern Illinois Planning Commission. "1990 Census of Population and Housing." Research Services Department, Aurora, IL., 1993.

Padilla, Félix M. Latino Ethnic Consciousness: The Case of Mexican Americans and Puerto Ricans in Chicago. Notre Dame: University of Notre Dame Press, 1985.

Palmer, Susan. "Building Ethnic Communities in a Small City: Romanians and Mexicans in Aurora, IL., 1900-1940." Ph.D. dissertation, Northern Illinois University, 1986.

Paral, Rob. "Suburban Immigrant Communities: Assessments of Key Characteristics and Needs." Prepared for The Fund for Immigrants and Refugees, Chicago, IL, 2000.

Perez, Bertha. "Dropouts: The Need For a Latino Community Response." Roberto E. Villarreal and Norma G. Hernandez (eds.). Latinos and Political Coalitions: Political Empowerment for the 1990s. New York: Greenwood Press, 1991.

Portes, Alejandro and Robert D. Manning. "The Immigrant Enclave: Theory and Empirical Examples." Joane Nagel and Susan Olzak (eds.). Competitive Ethnic Relations. New York: Academic Press, 1986.

Richard Lawrence Nelson \& Associates, Inc. Housing Conditions of Minority Groups in Aurora, IL. Richard Lawrence Nelson \& Associates, Inc., Chicago, IL., 1986.

Rios, Jr. Sam. "La Chicanada: Conflicts in Enculturation, Socialization, and Education." Young I. Song and Eugene C. Kim (eds.). American Mosaic: Selected Readings on America's Multicultural Heritage. Englewood Cliffs: Prentice Hall, 1993. 
Thornburg-Resistance

Saenz, Rogelio. "Exploring the Regional Diversity of Chicanos." Young I. Song and Eugene C. Kim (eds.). American Mosaic: Selected Readings on America's Multicultural Heritage. Englewood Cliffs: Prentice Hall, 1993.

Shorris, Earl. "Latinos: The Complexity of Identity." NACLA: Report on the Americas 26 (1992): 19-26.

So, A.Y. "Hispanic Education in the 1980s: Issues and Analysis." U.S. Resources in Education: ERIC Document ED. 1985. Song, Young I. and Eugene C. Kim (eds.). American Mosaic: Selected Readings on America's Multicultural Heritage. Englewood Cliffs: Prentice Hall, 1993.

Smart, Barry. Postmodernity. London: Routledge, 1993.

Strategy Research Corporation. "1991 U.S. Hispanic Market." Strategy Research Corporation, Miami, FL., 1991.

Tienda, Marta. "Puerto Ricans and the Underclass Debate." Ronald Takaki (ed.). From Different Shores: Perspectives on Race and Ethnicity in America. New York: Oxford University Press, 1987.

Vigil, James Diego. Barrio Gangs: Street Life and Identity in Southern California. Austin: University of Texas Press, 1988.

Yzaguirre, Raul. "Keys to Hispanic Empowerment." Roberto E. Villarreal and Norma G. Hernandez (eds.). Latinos and Political Coalitions: Political Empowerment for the 1990s. New York: Greenwood Press, 1991. 